\title{
El relato de los contextos históricos, sociales y políticos en las sentencias de la Corte Interamericana
}

Fecha de recepción: 1 de febrero de 2019

Fecha de aceptación: 3 de octubre de 2019

Doi: https://doi.org/10.12804/revistas.urosario.edu.co/acdi/a.7647

\section{Álvaro Paúl ${ }^{*}$}

Resumen: las sentencias de la Corte Interamericana de Derechos Humanos describen en detalle los hechos de los casos que tratan. Al hacerlo, suelen referirse no solo a los actos que afectaron a la víctima, sino también al contexto de tales hechos. Esta descripción del contexto puede tener efectos declarativos serios y utilizarse como base de una presunción en contra del Estado. Por eso, este trabajo analiza el uso del contexto y las dificultades que implica. Además, advierte que la Corte debe ser cuidadosa en su utilización.

Palabras clave: contexto, prueba, presunciones, Corte Interamericana de Derechos Humanos.

* Doctor en derecho por Trinity College Dublin, máster en derecho (MJur) por la Universidad de Oxford, y graduado de la Universidad de los Andes (Chile). El autor ha sido pasante o visitante de estudios en la Corte Interamericana de Derechos Humanos, la Comisión Interamericana de Derechos Humanos y el Tribunal Europeo de Derechos Humanos. Profesor Asociado de la Facultad de Derecho de la Pontificia Universidad Católica de Chile, Santiago.

Para citar este artículo: Paúl, Álvaro, "El relato de los contextos históricos, sociales y políticos en las sentencias de la Corte Interamericana”. Anuario Colombiano de Derecho Internacional (ACDI) 13, 2020, 19-46. https:// doi.org/10.12804/revistas.urosario.edu.co/acdi/a.7647 
The Description of Historical, Social and Political Contexts in the Decisions of the Inter-American Court

Abstract: The decisions of the Inter-American Court of Human Rights give detailed accounts of the human rights violations about which it decides. When doing so, it often refers to the context in which these violations occurred. The description of the context has serious declarative effects and may be useful as the basis for a presumption against the State. This paper analyzes the Court's use of context and describes some difficulties that it entails, and it claims that the Court must be cautious when referring to it.

Keywords: Context, evidence, presumptions, Inter-American Court of Human Rights.

O relato dos contextos históricos, sociais e políticos nas sentenças da Corte Interamericana

Resumo: as sentenças da Corte Interamericana de Direitos Humanos descrevem em detalhe os factos dos casos de que tratam. Ao fazê-lo, tendem a referir-se não só aos atos que afetaram à vítima, mas também ao contexto de esses factos. Esta descrição do "contexto" pode ter efeitos declarativos sérios e empregar-se como base de uma presunção contra o Estado. Por isto, este trabalho analisa o uso do contexto, e as dificuldades que leva, e adverte que a Corte deve ser cuidadosa em sua utilização.

Palavras-chave: contexto, prova, presunções, Corte Interamericana de Direitos Humanos. 


\section{Introducción}

Al sancionar a un Estado por un acto particular de violación de derechos humanos no es irrelevante que ese acto se haya cometido en un contexto de violaciones masivas. Tampoco carecen de importancia las circunstancias al aplicar el derecho internacional. Estas afirmaciones son compartidas por la Corte Interamericana de Derechos Humanos (Corte IDH). Es por eso que la Corte IDH ha relatado, desde sus primeros fallos, hechos de contexto que sirven para entender mejor los casos que ella decide y la gravedad de los mismos. Esto puede observarse desde su primera sentencia de fondo, en el caso Velásquez Rodríguez. c. Honduras. ${ }^{1}$ Hoy en día, en muchas ocasiones, la Corte IDH contempla en sus fallos una sección dedicada a relatar el contexto en el que ocurren ciertas violaciones.

Sin perjuicio de lo anterior, incluir una sección de contexto en una sentencia puede ser problemático, ya sea por su uso como mecanismo para referirse a cuestiones que exceden la competencia de una corte, por la escasa prueba que se utiliza para determinar dichos antecedentes o porque la extensión y colorido de la sección de contexto pueden generar la impresión de parcialidad del juzgador. Algunos de estos problemas en el uso del contexto se han observado en las sentencias de la Corte IDH. Por ello, este trabajo busca analizar detalladamente la sección de las sentencias interamericanas que describen el contexto, para mostrar los usos que esta le $\mathrm{da}$, resaltar algunas complejidades que presenta y advertir que el relato del contexto debe hacerse cuidadosamente. Esto permitirá al lector determinar si es necesario que la Corte IDH se replantee el modo como describe las circunstancias que rodean las violaciones de derechos humanos.

\section{El contexto en los casos ante la Corte IDH}

\subsection{Definición}

Atendida la prácticamente inexistente literatura sobre la descripción del contexto en las sentencias de la Corte IDH, antes de entrar de lleno en el contenido de este trabajo, señalaremos qué es el contexto. La Corte IDH afirmó en el caso Cabrera y Montiel c. México que en casos en los que se alegue "la existencia de patrones o prácticas de violaciones de derechos

Velásquez Rodríguezc. Honduras (1988): Corte IDH, Fondo, Serie C no. 4, párr. 147.a-147.d. 
humanos de carácter masivo, sistemático o estructural"2 no puede pretenderse aislar el contexto de los hechos de un caso concreto. Por eso, es necesario referirse a "las circunstancias históricas, materiales, temporales y espaciales en que ocurrieron los hechos alegados". ${ }^{3}$ Además, señala que los hechos del contexto son "parte de lo alegado por las partes", ${ }^{4}$ por lo que deberían ser probados por las partes.

Teniendo en cuenta la acepción de contexto ${ }^{5}$ y lo que ha dicho la Corte IDH en sus fallos, es posible proponer una definición para dicho concepto ante ella. El contexto sería el entorno político, histórico, cultural o de cualquier otra índole, que sea relevante para la resolución de un caso complejo sobre violaciones de derechos humanos, particularmente cuando se alegue la existencia de patrones de violaciones de carácter masivo, sistemático o estructural.

Aunque no es algo que haga en todas sus sentencias, la Corte IDH suele relatar el contexto de un caso en una subsección específica de sus sentencias, dentro de otra sección —más amplia— llamada Hechos probados o Hechos. ${ }^{6}$ La subsección del contexto suele llamarse Contexto o Antecedentes, ${ }^{7}$ aunque en ocasiones puede tener nombres más generales, por ejemplo, Situación de defensores del medio ambiente en..., ${ }^{8}$ o estar en varios títulos dentro de los Hechos, ${ }^{9}$ o encontrarse sin título, dentro

2 Cabrera García y Montiel Flores c. México (2010): Corte IDH, Excepción Preliminar, Fondo, Reparaciones y Costas, Serie C no. 220, párr. 63.

3 Ibíd., párr. 63.

4 Ibíd., párr. 64.

5 El diccionario de la Real Academia Española, en su segunda acepción, que es la relevante para efectos de este artículo, define el contexto como el "[e]ntorno físico o de situación, político, histórico, cultural o de cualquier otra índole, en el que se considera un hecho".

6 V.gr., Terrones Silvay otros c. Perú (2018): Corte IDH, Excepciones Preliminares, Fondo, Reparaciones y Costas, Serie C no. 360, título que antecede al párrafo 46.

7 V.gr., Tribunal Constitucional (Camba Campos y otros) c. Ecuador (Caso del) (2013): Corte IDH, Excepciones Preliminares, Fondo, Reparaciones y Costas, Serie C no. 268, título que antecede al párr. 40; Miembros de la Aldea Chichupac y comunidades vecinas del Municipio de Rabinal c. Guatemala (2016): Corte IDH, Excepciones Preliminares, Fondo, Reparaciones y Costas, Serie C no. 328, título que antecede al párr. 76.

8 Cfr. Luna López c. Honduras (2013): Corte IDH, Fondo, Reparaciones y Costas, Serie C no. 269, título que antecede al párr. 17.

9 V.gr., Pueblos Kaliña y Lokono c. Surinam (2015): Corte IDH, Fondo, Reparaciones y Costas, Serie C no. 309, título que antecede al párr. 29 y ss. 
de los hechos probados. ${ }^{10}$ También ha ocurrido que la Corte utiliza conjuntamente las expresiones antecedentes y contexto, ${ }^{11}$ o que se refiere a estas como dos secciones distintas. ${ }^{12}$ En ocasiones, esta pluralidad de nombres puede generar confusiones. ${ }^{13}$

\subsection{Cuestiones generales}

La Corte IDH considera positivo referirse al contexto histórico, social o político de los casos, pues ello permite "situar los hechos alegados como violatorios de la Convención Americana en el marco de las circunstancias específicas en que ocurrieron" 14 y caracterizar "los hechos como parte de un patrón sistemático de violaciones a los derechos humanos, como una práctica aplicada o tolerada por el Estado o como parte de ataques masivos y sistemáticos o generalizados hacia algún sector de la población". ${ }^{15}$ Según la Corte, al valorar el contexto, ella "no pretende emitir un pronunciamiento sobre los fenómenos globales relacionados con un determinado caso, ni juzgar las diversas circunstancias comprendidas en ese contexto". ${ }^{16}$ Sin embargo, atendiendo a que no parece posible describir realidades humanas

10 Abrill Alosilla y otros c. Perú (2011): Corte IDH, Fondo, Reparaciones y Costas, Serie C no. 235, párr. 80 .

11 Hermanas Serrano Cruz c. El Salvador (Caso de las) (2005): Corte IDH, Fondo, Reparaciones y Costas, Serie C no. 120, título que antecede al párr. 48.

12 V.gr., Trabajadores de la Hacienda Brasil Verde c. Brasil (2016): Corte IDH, Excepciones Preliminares, Fondo, Reparaciones y Costas, Serie C no. 318, títulos que anteceden a los párrs. 110 y 128; García Lucero y otras c. Chile (2013): Corte IDH, Excepción Preliminar, Fondo y Reparaciones, Serie C no. 267, párrs. 56-66.

13 Además del caso García Lucero, recién mencionado, se puede dar como ejemplo el de la Operación Génesis, donde la sentencia tiene un título "A. Contexto", y un título "B. Antecedentes de las Operaciones 'Génesis' y 'Cacarica”, con lo que no se sabe si el título de los antecedentes de las operaciones forma parte del contexto o si es una sección dedicada a hechos más remotos del caso a resolver. Comunidades Afrodescendientes desplazadas de la Cuenca del Río Cacarica (Operación Génesis) c. Colombia (2013): Corte IDH, Excepciones Preliminares, Fondo, Reparaciones y Costas, Serie C no. 270, títulos que anteceden a los párrs. 83 y 95.

14 López. Loney Otros c. Honduras (2015): Corte IDH, Excepción Preliminar, Fondo, Reparaciones y Costas, Serie C no. 302, párr. 43.

15 Ibíd.

16 Cabrera García y Montiel Flores c. México (2010): Corte IDH, Excepción Preliminar, Fondo, Reparaciones y Costas, Serie C no. 220, párr. 64. 
relacionadas con violaciones a los derechos humanos sin hacer un cierto juicio sobre las mismas, podría decirse que esta última afirmación de la Corte IDH no es del todo convincente.

Complementando lo anterior, la Corte IDH se ha referido a los usos que ella le ha dado al contexto. Ha señalado que el contexto ha sido "tenido en cuenta para la determinación de la responsabilidad internacional del Estado, la comprensión y valoración de la prueba, la procedencia de ciertas medidas de reparación y los estándares establecidos respecto de la obligación de investigar dichos casos". ${ }^{17}$ Como se puede apreciar en esta cita, serían cuatro las aplicaciones que la Corte IDH le da al contexto. Estas serán comentadas en la próxima sección.

Se ha afirmado que el contexto se refiere a situaciones conocidas por todos, o incluso hechos notorios. ${ }^{18}$ Sin embargo, la práctica de la Corte IDH muestra que el contexto no solo se refiere a hechos generalmente aceptados, sino que incluye hechos que pueden ser discutidos. Así, por ejemplo, en el caso Rodríguez, Vera (Desaparecidos del Palacio de Justicia) c. Colombia, el Estado afirmó expresamente que su reconocimiento de responsabilidad no implicaba admitir las circunstancias que habían sido presentadas como parte del contexto. ${ }^{19}$

En general, la descripción del contexto afectará a los Estados, no a las víctimas. Por eso, serán aquellos los que se preocuparán de lo que la Corte IDH declare como parte del contexto. Así, por ejemplo, en el caso Cabreray Montiel c. México, la Comisión y los representantes buscaban que ciertos actos de tortura y abusos fueran incluidos como elementos de contexto; el Estado se opuso, alegando que dichos hechos se encontraban fuera del objeto del caso y que solo buscaban ampliar la litis a hechos ajenos al asunto. ${ }^{20}$ En ese mismo caso, para la eventualidad de que se considerara que dichos hechos formaban parte del contexto, el Estado

17 López Loney Otros c. Honduras (2015): Corte IDH, Excepción Preliminar, Fondo, Reparaciones y Costas, Serie C no. 302, párr. 43.

18 Humberto Sierra Porto, "La Utilización del Contexto en la Jurisprudencia de la Corte Interamericana de Derechos Humanos", grabado marzo 29 de 2016 en la Universidad Pompeu Fabra, Barcelona, España, video, 4:43-5:06, https://www.youtube.com/ watch? $=8 \mathrm{x} 1 \mathrm{vIVAP} 8 \mathrm{VU}$

19 Rodriguez Vera y otros (Desaparecidos del Palacio de Justicia) c. Colombia (2014): Corte IDH, Excepciones Preliminares, Fondo, Reparaciones y Costas, Serie C no. 287.

20 Cabrera García y Montiel Flores c. México (2010): Corte IDH, Excepción Preliminar, Fondo, Reparaciones y Costas, Serie C no. 220, párr. 62. 
de México presentó argumentos para desvirtuar lo que consideraba ser meras "generalizaciones sin fundamento". ${ }^{21}$

\subsection{Usos que la Corte da al contexto}

\subsubsection{Elemento para determinar la responsabilidad internacional del Estado}

En alguna ocasión la Corte IDH señaló que "no derivará ninguna consecuencia jurídica" de los antecedentes. ${ }^{22}$ Sin embargo, según se afirmó en el apartado anterior, como regla general la Corte IDH afirma darle cuatro usos al contexto. En esta sección se revisará su uso "para la determinación de la responsabilidad internacional del Estado". ${ }^{23}$ Esta afirmación puede entenderse de tres formas. La primera, considerando el contexto como un elemento que determina la gravedad de la responsabilidad del Estado, en el sentido de calificar la naturaleza de la violación cometida por este (por ejemplo, que un asesinato sea o no calificado de delito de lesa humanidad, lo que dependerá de que haya sido "parte de un ataque generalizado o sistemático contra una población civil”). ${ }^{24} \mathrm{La}$ segunda, como un elemento que forme parte necesaria del razonamiento que efectúa la Corte IDH para determinar la responsabilidad del Estado (por ejemplo, que sea utilizado como indicio de una violación). La tercera forma de entenderla es como un elemento que califica inmediatamente como violación los hechos que afectan a un grupo de personas, como afirmó la Corte IDH en el caso López Lone: "La Corte advierte que, en virtud de este contexto, los hechos de este caso evidentemente afectaron un conjunto de derechos de las presuntas víctimas". ${ }^{25}$

\footnotetext{
21 Ibíd.

22 Comunidad Indígena Xákmok Kásek c. Paraguay (2010): Corte IDH, Fondo, Reparaciones y Costas, Serie C no. 214, párr. 55.

23 López. Lone y otros c. Honduras (2015): Corte IDH, Excepción Preliminar, Fondo, Reparaciones y Costas, Serie C no. 302, párr. 43.

24 Artículo 7.1. del Estatuto de Roma de la Corte Penal Internacional.

25 López Lone y otros c. Honduras (2015): Corte IDH, Excepción Preliminar, Fondo, Reparaciones y Costas, Serie C no. 302, párr. 155. Dicha cita daría sustento a la afirmación que el contexto opera "como fundamento de condena, el cual se manifiesta como una moderna denominación del indicio ante la ausencia de otros medios de prueba vinculados en el debate probatorio".
} 
Pensamos que es más apropiado entenderla del primer modo. Ello, por una parte, porque el segundo está íntimamente relacionado con el uso del contexto para "la comprensión y valoración de la prueba" (que se analizará posteriormente), y por otro lado, el tercer uso que se podría hacer del contexto raya en un prejuzgamiento, por lo que no parece adecuado. Por ello, entenderemos que cuando la Corte IDH se refiere al uso del contexto para determinar la responsabilidad del Estado, se está refiriendo, principalmente, a su uso para calificar la naturaleza de la violación como de lesa humanidad.

Como decíamos, un ejemplo del uso del contexto para calificar la naturaleza de una violación, sería el que la Corte IDH pueda determinar si el caso en estudio se trata de una manifestación individual de una violación masiva de derechos humanos. Ello, por cuanto no es lo mismo que un agente policial estatal torture a un detenido en una manifestación aislada de abuso individual, que si dicha tortura es cometida como parte de una política estatal. En caso de que se tratara de una práctica masiva, podrían alegarse ciertos deberes estatales asociados a las violaciones de lesa humanidad, como podría ser la prohibición de amnistías — según los criterios establecidos por la Corte IDH - o la referencia al derecho a la verdad. ${ }^{26}$

\subsubsection{Elemento para comprender y valorar la prueba}

La Corte IDH también dice usar el contexto para la comprensión y valoración de la prueba. Esta afirmación parece querer decir que el contexto sirve para valorar las pruebas dentro de un marco que las haga más comprensibles y permita analizarlas según su verdadero significado, siguiendo las reglas de la sana crítica. ${ }^{27}$ Además, puede significar que el contexto podría, una vez probado, transformarse en prueba circunstancial o en

Luisa Fernanda Castañeda Quintana, "El contexto como materialización de la prueba indiciaria en la Corte Interamericana de Derechos Humanos", Revista Nueva Época 37, (2011): 99-100.

26 Algunos consideran que el derecho a la verdad solo puede configurarse respecto a las violaciones graves a los derechos humanos y no respecto a violaciones más ordinarias. Por ejemplo, Comisión Interamericana de Derechos Humanos, Derecho a la verdad en América, (OEA/Ser.L/V/II.152, Doc. 2, 2014), http://www.oas.org/es/cidh/informes/pdfs/ Derecho-Verdad-es.pdf, 6

27 La Corte IDH suele afirmar que ella analiza las pruebas conforme a la sana crítica, una vez que todas ellas han sido integradas al acervo probatorio —el que se considera como 
base de una presunción. ${ }^{28}$ Ello justificaría que se haya afirmado que el contexto es un indicio. ${ }^{29}$

Dentro de la utilidad del contexto como base para una presunción cobra especial relevancia el uso que la Corte IDH le da como parte integrante del "razonamiento probabilístico para probar violaciones de derechos humanos". ${ }^{30}$ Dicha forma de razonar permite que la Corte IDH invierta la carga de la prueba cuando se cumplen dos requisitos: que se observe la existencia de una violación masiva de los derechos humanos que afecta a una categoría específica de personas, y que se pueda incluir a las presuntas víctimas dentro de dicha categoría específica. ${ }^{31}$ Esta técnica ha sido muy útil para dar por probada la responsabilidad estatal en casos de desapariciones forzadas.

La Corte IDH también ha considerado algún elemento del contexto como componente del incumplimiento estatal de la Convención Americana de Derechos Humanos. Por ejemplo, en el caso de los Hermanos Landaeta $c$. Venezuela, la Corte consideró la "problemática de abusos policiales en dicha época" como uno de los "elementos concatenados que configuran un incumplimiento por parte del Estado a su deber de respeto y garantía a favor de Eduardo Landaeta". ${ }^{32}$ En este último caso, cabe preguntarse si este contexto no sería — más que un simple antecedente- un elemento fundamental del proceso, que debiera probarse como cualquier otro elemento de fondo.

un todo- V. Vr., entre muchos otros, Furlan y Familiares c. Argentina (2012): Corte IDH, Excepciones Preliminares, Fondo, Reparaciones y Costas, Serie C no. 246, párr. 65.

28 Taruffo afirma que lo que se suele denominar circumstantial evidence en los sistemas anglófonos, se suele denominar presunción en España y présomption de l'bomme en Francia. Michele Taruffo, La prueba, (Madrid: Marcial Pons, 2008), 104-105.

29 Castañeda, "El Contexto como materialización...", 114.

30 Álvaro Paúl Díaz, "Razonamiento probabilístico de la Corte Interamericana para probar violaciones ocurridas en un contexto de atropellos masivos". Anuario de Derecho, 29 (2012): 45.

31 Ibíd., 46.

En este sentido, la Corte IDH afirmó en el caso de Juan Humberto Sánchez "que si se demuestra para el caso concreto que este obedecía al patrón de ejecuciones extrajudiciales, es razonable presumir y concluir que existe responsabilidad internacional del Estado". Sánchez, Juan Humberto c. Honduras (2003): Corte IDH, Excepción Preliminar, Fondo, Reparaciones y Costas, Serie C no. 99, párr. 108.

32 V.gr., Hermanos Landaeta Mejías y Otros c. Venezuela (2014): Corte IDH, Excepciones Preliminares, Fondo, Reparaciones y Costas, Serie C no. 281, párr. 196. 


\subsubsection{Elemento necesario para determinar la procedencia de ciertas reparaciones}

La Corte IDH es conocida por su originalidad en la concesión de reparaciones, que incluyen ordenar el pago de indemnizaciones, la reintegración a puestos de trabajo, la anulación de sentencias, tratamientos médicos y psicológicos, la modificación de leyes —incluso de la constitución política一, la creación de programas médicos o de viviendas, la concientización de personas en temas de derechos humanos, la erección de monumentos y el nombramiento de edificios en honor de las víctimas, entre otros. ${ }^{33}$

Dentro de estas amplias reparaciones, son particularmente interesantes para nuestro estudio las llamadas garantías de no repetición. Estas son medidas "ordenadas judicialmente a un Estado cuyo contenido está encaminado a eliminar de manera directa una deficiencia estructural del sistema nacional que está permitiendo o favoreciendo violaciones reiterativas a los derechos humanos". ${ }^{34}$ Las garantías de no repetición pueden incluir medidas que son ordinariamente propias del poder ejecutivo, legislativo o judicial. ${ }^{35}$

A un lector que sea ajeno al sistema interamericano puede llamarle la atención que la Corte IDH ordene medidas de no repetición, en atención a que, según ha afirmado la Corte Internacional de Justicia, aunque ella

puede ordenar, como lo ha hecho en el pasado, a un Estado responsable por una conducta internacionalmente ilícita que provea al Estado afectado con seguridades y garantías de no repetición, lo hará solo si las circunstancias así lo exigen, lo que debe ser evaluado por la Corte. // Como regla general, no hay razón para suponer que un Estado cuyo acto o conducta haya sido declarado ilícito por la Corte vaya a repetir ese acto o conducta en el futuro, ya que su buena fe debe presumirse. ${ }^{36}$

33 Para una descripción de diversos tipos de reparaciones, véase: Thomas M. Antkowiak, "Remedial Approaches to Human Rights Violations: The Inter-American Court of Human Rights and Beyond", Columbia Journal of Transnational Law, 46 (2008): 371-87.

34 María Carmelina Londoño Lázaro, Las garantías de no repetición en la jurisprudencia interamericana. Derecho internacionaly cambios estructurales del Estado, (México D.F.: Tirant lo Blanch, 2014), 103-04.

35 Ibíd., 107.

36 Costa Rica c. Nicaragua (2009): Corte Internacional de Justicia, Sentencia, 13 de julio, párr. 150 (la traducción es del autor). La segunda parte de dicha afirmación puede leerse 
En otras palabras, el principio de buena fe — que guía el derecho internacional - haría presumir que una vez notificado el Estado de una sentencia condenatoria, este hará lo posible por evitar ese tipo de acciones que violan los derechos humanos. Sin embargo, la Corte IDH no saca esta consecuencia práctica del principio de buena fe, por lo que ordena garantías de no repetición en gran parte de los casos que decide. ${ }^{37}$ Esto sería consistente con la práctica de otros órganos del ámbito de los derechos humanos. ${ }^{38}$

Las garantías de no repetición son particularmente relevantes para nuestro estudio en atención a que, usando estas medidas, la Corte IDH ha ordenado la realización de actos que implican decisiones de políticas públicas. ${ }^{39}$ Los fallos que contienen este tipo de órdenes han sido llamados por algunos "sentencias intermedias", es decir, en palabras del juez Sierra Porto, "sentencias que son mitad jurisprudenciales y mitad políticas públicas". ${ }^{40}$ Dicho juez afirma que tales sentencias suponen, como garantías de no repetición, elaborar políticas públicas para resolver las cuestiones fácticas que determinaron la vulneración de los derechos humanos. ${ }^{41}$

Que un tribunal vaya más allá de su tarea de resolver conflictos y se embarque en una misión que es más acorde con funciones ejecutivas y legislativas puede dar lugar a diversas críticas. Sin embargo, nosotros no nos referiremos a ellas. ${ }^{42}$ Este trabajo solo hace presente que para poder dictar medidas que impliquen la toma de decisiones de políticas públicas, un tribunal debe conocer muy bien la situación del país en la materia. Por eso, la Corte IDH debe estudiar las situaciones que podrían requerir un cambio en materia de políticas públicas y la sección de contexto sería el

también en Alemania c. Italia (2012): Corte Internacional de Justicia, Sentencia, 3 de febrero, párr. 138.

37 Londoño, Las garantías de no repetición..., 323-398.

Especialmente en los casos más recientes, donde podría decirse, incluso, que la mayoría de las sentencias ordenan medidas de no repetición.

38 Naomi Roht-Arriaza, "Measures of Non-Repetition in Transitional Justice. The Missing Link?", en From Transitional to Transformative Justice editado por Paul Gready y Simon Robins, (Cambridge University Press, 2019), 114-17.

39 Sobre los distintos tipos de medidas de no repetición, véase Ibíd., 134-88.

40 Sierra, "La utilización del contexto...", 35:53-36:04.

$41 \quad$ Ibíd., 35:53-37:43.

42 Para algunos de los posibles efectos adversos de estas medidas, véase: Londoño, Las garantías de no repetición..., 306-10. 
resultado de dicho estudio. La pregunta que cabe hacerse, sin embargo, es si la Corte IDH es la entidad más indicada para tomar este tipo de decisiones.

\subsubsection{Elemento para determinar la extensión de la obligación de investigar}

El cuarto uso del contexto también se relaciona con las reparaciones del caso, pero ya no con las medidas de no repetición, sino con la obligación de investigar las violaciones a los derechos humanos. En esta materia, según el juez Sierra Porto, la Corte IDH ha declarado que los Estados han violado el debido proceso si investigan algunos asuntos como casos aislados, aun cuando tales casos sigan patrones que forman parte de un contexto más generalizado de violaciones. ${ }^{43}$ Sierra Porto considera que hay tres casos que se ajustan a lo anterior: Campo Algodonero c. México, Masacre de La Rochela c. Colombia y Contreras c. El Salvador. ${ }^{44}$

Para entender mejor este uso del contexto, tomaremos uno de los casos citados por el juez Sierra Porto: Campo Algodonero c. México. Dicho asunto trató sobre las muertes de tres mujeres jóvenes, cuyos cuerpos fueron encontrados el mismo día en un campo algodonero de Ciudad Juárez. ${ }^{45}$ Tales muertes tenían como contexto "un fenómeno complejo $[\ldots]$ de violencia contra las mujeres" que comenzó en $1993^{46}$. No obstante, dichas muertes fueron investigadas en forma independiente a nivel interno. Por eso, la Corte IDH recalcó que si las líneas de investigación “eluden el análisis de los patrones sistemáticos en los que se enmarcan cierto tipo de violaciones a los derechos humanos, pueden generar ineficacia en las investigaciones". ${ }^{47}$ Atendiendo a que en estos casos no se encontraron "decisiones del Ministerio Público dirigidas a relacionar estas indagaciones con los patrones en los que se enmarcan las desapariciones de otras mujeres", ${ }^{48}$ la Corte IDH reprochó al Estado lo inadmisible que era "que no exis[tiera] una mínima valoración judicial de los efectos del contexto

\footnotetext{
43 Sierra, "La utilización del contexto...", 35:53-36:04 y 31:00-32:50.

$44 \quad$ Ibíd., 32:37-32:50.

45 Gonzálezy otras ("Campo Algodonero") c. México (2009): Corte IDH, Excepción Preliminar, Fondo, Reparaciones y Costas, Serie C no. 205, párr. 2.

46 Ibíd., párr. 121.

47 Ibíd., párr. 366.

48 Ibíd., párr. 369.
} 
respecto a las investigaciones por estos homicidios". ${ }^{49}$ Asimismo, resaltó la importancia de aplicar sanciones para controlar la actuación de funcionarios del Estado, "particularmente cuando las violaciones de derechos humanos responden a patrones generalizados y sistemáticos". ${ }^{50}$

\subsection{Uso del contexto por parte de otros tribunales internacionales}

La Corte IDH no es el único tribunal internacional que hace uso del contexto. En efecto, en mayor o menor medida también lo hacen la Corte Internacional de Justicia (CIJ) ${ }^{51}$ y el Tribunal Europeo de Derechos Humanos (TEDH).$^{52}$ Es interesante analizar las diferencias en el modo como estos tribunales tratan el tema. La CIJ relata el contexto en forma más o menos extendida, pero a diferencia de lo que ocurre con la Corte IDH, no indica expresamente cuál es la fuente desde donde obtiene la información que incluye en el contexto. ${ }^{53}$ En ese sentido, es mejor el sistema usado por la Corte IDH. Sin embargo, esta afirmación debe relativizarse, teniendo en cuenta que los hechos afirmados por la CIJ suelen ser generales y de fácil comprobación.

Por su parte, el TEDH incluye dentro de las circunstancias del caso tanto los aspectos más personales de la presunta víctima, como otros

\footnotetext{
49 Ibíd., párr. 369.

50 Ibíd., párr. 373.
}

Otro caso en el que la Corte IDH afirmó expresamente que debe tenerse en consideración el contexto al momento de realizar la investigación es González. Medina y Familiares c. República Dominicana (2012): Corte IDH, Excepciones Preliminares, Fondo, Reparaciones y Costas, Serie C no. 240, párr. 285.a.

51 Abmadou Sadio Diallo (República de Guinea c. República Democrática del Congo) (2010): CIJ, Sentencia, 30 de noviembre; Alemania c. Italia (2012): CIJ, Sentencia, 3 de febrero; Bolivia c. Chile (2018): CIJ, Sentencia, 1 de octubre; Costa Rica c. Nicaragua (2009): CIJ, Sentencia, 13 de julio.

52 AlNashiric. Polonia (2011): TEDH, 28761/11, 30 de noviembre; Big Brother Watch c. El Reino Unido (2018): TEDH, 58170/13, 62322/14 y 24960/15, 13 de septiembre, y Refah Partisi (The Welfare Party) y otros c. Turquia (2003): TEDH, 41340/98, 41342/98, 41343/98 y 41344/98, 13 de febrero.

53 Véase, v.gr., Abmadou Sadio Diallo (República de Guinea c. República Democrática del Congo) (2010): CIJ, Sentencia, 30 de noviembre, párrs. 15-19; Alemania c. Italia (2012): CIJ, Sentencia, 3 de febrero, párrs. 20-36; Bolivia c. Chile (2018): CIJ, Sentencia, 1 de octubre, y Costa Rica c. Nicaragua (2009): CIJ, Sentencia, 13 de julio, párrs. 16-83. 
relacionados con el contexto del asunto tratado. Dicho tribunal restringe su relato del contexto a los hechos verdaderamente indispensables, lo que contrasta con la práctica de la Corte IDH, donde son excepcionales las descripciones acotadas, aunque se observan excepciones como en el caso Abrill Alosilla y otros c. Perú, donde el relato del contexto fue bastante somero: se llevó a cabo en un solo párrafo. ${ }^{54}$

La CIJ no usa el contexto como mecanismo para dar por probados ciertos hechos sobre la base de un razonamiento probabilístico. La naturaleza interestatal de los procedimientos de dicho tribunal puede explicar que no se den por probados los hechos haciendo dicho razonamiento, pues no suele analizar casos particulares que formen parte de violaciones sistemáticas. En el caso del TEDH, al contexto se le puede dar un valor relevante en materia probatoria ${ }^{55} \mathrm{o}$ se puede usar para mostrar los peligros que puede presentar una determinada acción. ${ }^{56}$

\section{Dificultades que presenta el uso del contexto por parte de la Corte IDH}

\subsection{Incompetencia o falta de bilateralidad al describir el contexto}

\subsubsection{Constatación de violaciones respecto de las cuales la Corte IDH no tiene competencia}

Uno de los grandes problemas generados por el análisis del contexto es que la Corte IDH puede usar dicho estudio para modificar, en la práctica, los límites de su competencia en cuanto al tiempo. En efecto, esta solo puede conocer de violaciones ocurridas con posterioridad a la fecha en que los Estados parte de la Convención Americana le concedieron competencia. ${ }^{57}$ Sin embargo, haciendo uso del contexto, la Corte IDH ha declarado la comisión de violaciones en fechas anteriores a las de su competencia. Por

\footnotetext{
54 Abrill Alosilla y Otros c. Perú (2011): Corte IDH, Fondo, Reparaciones y Costas, Serie C no. 235, párr. 80.

55 V.gr., El-Masri c. Antigua República Yugoslava de Macedonia (2012): TEDH, 39630/09, 13 de diciembre, párr. 160.

56 V.gr., Sayği c. Turquia (2015): TEDH, 37715/11, 27 de enero.

57 Véase artículo 45 de la Convención Americana sobre Derechos Humanos.
} 
supuesto que la Corte IDH no ha afirmado en el contexto que los Estados hayan violado artículos específicos de la Convención Americana, pero ha declarado la ocurrencia de hechos que calzan perfectamente dentro de las tipificaciones de tales artículos. Es cierto que los Estados no verán comprometida su responsabilidad internacional por relatos de contexto (pues no podría declararse la violación de artículos específicos, en atención a la falta de competencia de la Corte ratione temporis), pero ello no hace inocuas tales declaraciones, pues a los Estados no solo les interesa que no se vea comprometida su responsabilidad, sino que también les importa que su reputación no sea puesta en entredicho.

Así, por ejemplo, en el caso Omar Humberto Maldonado Vargasy otros c. Chile, la Corte IDH no tenía competencia para referirse a las violaciones ocurridas antes de 1990 (en razón de la fecha en la que se aceptó la competencia de la Corte IDH, y en particular, por la declaración interpretativa presentada por Chile) $;^{58}$ no tenía competencia para conocer de actos de tortura, detención ilegal, etc., cometidos durante el régimen de Augusto Pinochet. Sin embargo, ello no impidió que, dentro de los "antecedentes" - o contexto-, esta declarara que el Estado de Chile había detenido ilegalmente y torturado a las víctimas de este caso, así como a miles de otras personas en el periodo excluido de su jurisdicción. En este caso, el Estado reconoció los hechos del contexto, lo que debe haber facilitado la decisión de la Corte IDH, ${ }^{59}$ pero esta también utilizó el "acervo probatorio con la finalidad de precisar algunos hechos señalados por las partes y la Comisión". ${ }^{60}$ Ahora, la pregunta es por qué sería necesario dar precisión a hechos respecto de los cuales no se tiene competencia.

Existen también otros casos de Chile donde la Corte se refiere a un contexto similar al relatado en Maldonado y otros. ${ }^{61}$ Particularmente

58 La fecha en que se depositó el instrumento de ratificación fue el 21 de agosto de 1990. La parte relevante de dicha declaración dispone: "Al formular las mencionadas declaraciones, el Gobierno de Chile deja constancia [de] que los reconocimientos de competencia que ha conferido se refieren a hechos posteriores a la fecha del depósito de este instrumento de ratificación o, en todo caso, a hechos cuyo principio de ejecución sea posterior al 11 de marzo de 1990".

59 Omar Humberto Maldonado Vargas y otros c. Chile (2015): Corte IDH, Fondo, Reparaciones y Costas, Serie C no. 300, párr. 19.

60 Ibíd., párr. 19.

61 V.gr., Almonacid Arellano y Otros c. Chile (2006): Corte IDH, Excepciones Preliminares, Fondo, Reparaciones y Costas, Serie C no. 154, párrs. 82.3-82.7, y García Lucero y otras c. 
interesante es el caso García Lucero y otras c. Chile, donde la sección de antecedentes, no obstante que la Corte IDH carecía de competencia para referirse a los actos de tortura sufridos por García, se refiere a ellos en gran detalle. ${ }^{62}$ La Corte IDH trata estos hechos dentro de los "antecedentes", pero ellos son demasiado específicos como para ser incluidos dentro de lo que puede definirse como contexto.

$\mathrm{Al}$ detallar la comisión de múltiples y serias violaciones de derechos humanos respecto de las cuales no tiene competencia, la Corte IDH termina imputándoselas al Estado. Nosotros no negamos que se hayan cometido serios actos de violación de derechos humanos en los contextos aludidos por la Corte IDH, solo afirmamos que esta no tiene competencia para conocer de tales actos, por lo que no debería referirse a ellos, al menos en el detalle en que lo hace. Si la Corte IDH hace pasar por contexto algunos hechos (bastante detallados) que están fuera del ámbito de su competencia, da la impresión de estar eludiendo las limitaciones de su jurisdicción. Además, podría estar afectando la bilateralidad de la audiencia, pues las partes no estaban en la obligación de exponer sus puntos de vista sobre el tema —atendido que la Corte IDH no tenía la competencia para referirse al mismo-, por lo que es posible que hayan guardado silencio sobre esos puntos del contexto.

\subsubsection{Constatación de violaciones o hechos respecto de un Estado que no es parte}

Otro elemento al que se debe prestar atención es que la relación del contexto involucre a terceros Estados, pues estos no han tenido la posibilidad de referirse a tales hechos y hacer sus descargos. Las referencias a terceros Estados pueden tratar de hechos accesorios, pero también de hechos que constituirían violaciones a los derechos humanos. En cualquier caso, esto iría en contra del principio de la bilateralidad de la audiencia, que es uno de los principios básicos del debido proceso.

Chile (2013): Corte IDH, Excepción Preliminar, Fondo y Reparaciones, Serie C no. 267, párrs. 56-60.

62 Habla de golpes, inmersiones en agua, amenazas, descargas eléctricas, etc. Ibíd., párr. 63. 
Existen varios ejemplos donde el contexto se refiere a hechos que afectan a terceros Estados, por ejemplo, en el caso Castillo González. c. Venezuela, el contexto trata de la situación en la frontera de Venezuela y Colombia: cómo muchos colombianos habrían sido desplazados a causa del conflicto armado. ${ }^{63}$ También relata que habría habido grupos armados irregulares en Colombia, en la frontera, causando "secuestros, sicariatos, extorsión, robos y contrabando", así como homicidios. ${ }^{64}$ Otro ejemplo se observa en el caso Goiburú y otros c. Paraguay, donde se afirma que la "Operación Cóndor" fue una alianza "de las dictaduras del Cono Sur en su lucha y represión contra personas designadas como 'elementos subversivos" ${ }^{\prime 65}$ en cuyo marco se habría producido la desaparición forzada de las víctimas iniciales del caso. Este contexto habría sido del interés de todos los Estados del Cono Sur, no solo de Paraguay, pues se afirma que todos ellos habrían concertado para violar derechos humanos. ${ }^{66}$

Es interesante que en el mismo caso Goiburú se habla de Estados Unidos, que ni siquiera es parte de la Convención Americana. Según la Corte IDH, la CIA y otras agencias de dicho Estado habrían apoyado la labor de las fuerzas de seguridad, militares y servicios de inteligencia del Cono Sur, ${ }^{67}$ y el FBI habría conocido de las acciones ilícitas de la Operación Cóndor. ${ }^{68}$

Atendido todo lo anterior, sería conveniente que la Corte IDH ideara un mecanismo según el cual invite a los Estados que no son parte del caso, pero que serán mencionados en el contexto, para que puedan emitir sus opiniones sobre la situación que será descrita. El establecimiento de un proceso como este solo requeriría modificar el reglamento de la Corte IDH.

63 Castillo Gonzálezy otros c. Venezuela (2012): Corte IDH, Fondo, Serie C no. 256, párr. 35.

64 Ibíd., párr. 36.

65 Goiburú y otros c. Paraguay (2006): Corte IDH, Fondo, Reparaciones y Costas, Serie C no. 153, párr. 61.6.

66 Por ejemplo, eso se observa en Ibíd., párrs. 61.8 y 61.12.

${ }^{67}$ Ibíd., párr. 61.6.

68 Ibíd., párr. 61.8. 


\subsection{Prueba usada para probar el contexto}

\subsubsection{Medios probatorios usados para probar el contexto}

Existen casos en que la Corte IDH no indica la fuente de donde obtuvo ciertos datos de contexto. En partes del caso Hermanas Serrano Cruz-una de las sentencias más antiguas donde se establece un título específico para la relación de datos de contexto- hay varias secciones donde esta no da a conocer las fuentes de las cuales obtiene cierta información. ${ }^{69}$ Asimismo, en el caso de los Trabajadores de la Hacienda Brasil Verde, se observa un párrafo con información histórica bastante detallada —incluyendo fechas y un porcentaje-, cuya fuente no se revela. ${ }^{70}$ No obstante, en la gran mayoría de los casos donde se establecen hechos de contexto, la Corte IDH detalla minuciosamente cuáles son los medios de prueba utilizados.

Uno de los mecanismos de convencimiento que utiliza la Corte IDH, y quizá uno de los más relevantes en casos de violaciones de lesa humanidad, es la referencia a los hechos probados en casos anteriores por ella misma. ${ }^{71}$ Este mecanismo consiste en hacer una referencia indirecta a los medios de prueba que se aportaron en un caso anterior. Esto se observa, por ejemplo, en el caso del Tribunal Constitucional (Camba Campos y otros) c. Ecuador, donde una parte significativa de las afirmaciones están basadas en la sentencia del caso Corte Suprema de Justicia (Quintana Coello y otros) c. Ecuador. ${ }^{72}$ Otro ejemplo es el caso Luna López, donde la Corte IDH se refiere a la situación de los defensores del medio ambiente en Honduras

69 Hermanas Serrano Cruzc. El Salvador (Caso de las) (2005): Corte IDH, Fondo, Reparaciones y Costas, Serie C no. 120, párrs. 48.1, 48.2, 48.6 y 48.7.

70 Trabajadores de la Hacienda Brasil Verde c. Brasil (2016): Corte IDH, Excepciones Preliminares, Fondo, Reparaciones y Costas, Serie C no. 318, párr. 110.

71 V.gr., Herzogy otros c. Brasil (2018): Corte IDH, Excepciones Preliminares, Fondo, Reparaciones y Costas, Serie C no. 353, párr. 107; Tribunal Constitucional (Camba Campos y otros) c. Ecuador (Caso del) (2013): Corte IDH, Excepciones Preliminares, Fondo, Reparaciones y Costas, Serie C no. 268, notas al pie 23-38; Luna López c. Honduras (2013): Corte IDH, Fondo, Reparaciones y Costas, Serie C no. 269, notas al pie 25-34; Coc Max y otros (Masacre de Xamán) c. Guatemala (2018): Corte IDH, Fondo, Reparaciones y Costas, Serie C no. 356, notas al pie 23-24 y 26-29.

72 Tribunal Constitucional (Camba Campos y otros) c. Ecuador (Caso del) (2013): Corte IDH, Excepciones Preliminares, Fondo, Reparaciones y Costas, Serie C no. 268, notas al pie 23-38. 
y, al hacerlo, da bastante importancia al caso Kawas Fernández. c. Honduras. ${ }^{73}$ En una ocasión, debido a que la Corte IDH hace imputaciones muy fuertes —afirma que en la década posterior a la muerte de Blanca Kawas se habían "reportado actos de agresión, amenazas y ejecuciones de varias personas dedicadas a la defensa del medio ambiente en Honduras"-, la Corte no solo citó dicho caso, sino que reiteró la prueba utilizada en él para probar lo que entonces reafirmaba. ${ }^{74}$

La práctica de recurrir a hechos probados en casos anteriores muestra que si las partes de un proceso estuvieran en contra de algunas de las conclusiones de la Corte IDH en casos previos, ellas deberían presentar prueba en contra. Si no lo hacen, esta puede reiterar lo resuelto en algún caso anterior. Para que la Corte IDH llegue a una conclusión contraria a la de un asunto previo, debe bastar con que la prueba aportada en un nuevo juicio sea más convincente que la del caso anterior.

La Corte IDH también suele recurrir con frecuencia a los informes elaborados por distintas instituciones, ${ }^{75}$ ya sean organismos internacionales, ${ }^{76}$ comisiones de verdad ${ }^{77}$ u organizaciones no gubernamentales. ${ }^{78}$ En ocasiones, puede utilizar estos informes en conjunto con otros medios de prueba como los peritajes. ${ }^{79}$ Generalmente, la Corte IDH utiliza informes de instituciones independientes, ${ }^{80}$ pero llama la atención que ella use

73 Luna López. c. Honduras (2013): Corte IDH, Fondo, Reparaciones y Costas, Serie C no. 269, notas al pie 25-34.

74 Ibíd., nota al pie 26.

75 V.gr., Herzog y otros c. Brasil (2018): Corte IDH, Excepciones Preliminares, Fondo, Reparaciones y Costas, Serie C no. 353, notas al pie 49, 53-55, 58-61, 63-68; Carvajal Carvajaly otros c. Colombia (2018): Corte IDH, Fondo, Reparaciones y Costas, Serie C no. 352, notas al pie 23, 24 y 30, entre muchas otras.

76 V.gr., Trabajadores de la Hacienda Brasil Verde c. Brasil (2016): Corte IDH, Excepciones Preliminares, Fondo, Reparaciones y Costas, Serie C no. 318, notas al pie 63-66.

77 Gudiel Alvarezy otros ("Diario Militar") c. Guatemala (2012): Corte IDH, Fondo, Reparaciones y Costas, Serie C N²53, nota al pie 48; Terrones Silva y otros c. Perú (2018): Corte IDH, Excepciones Preliminares, Fondo, Reparaciones y Costas, Serie C no. 360, notas al pie 35 y ss.

78 V.gr., Gonzálezy otras (“Campo Algodonero") c. México (2009): Corte IDH, Excepción Preliminar, Fondo, Reparaciones y Costas, Serie C no. 205, párr. 116.

79 V.gr., Comunidad Indigena Sawhoyamaxa c. Paraguay (2006): Corte IDH, Fondo, Reparaciones y Costas, Serie C no. 146, párrs 73.1-73.3.

80 V.gr., Ibíd., párrs 73.1-73.3. 
también informes de la Comisión Interamericana, pues esta comparece "como parte" en los casos ante la Corte IDH. ${ }^{81}$ También es llamativo que utilice informes emanados de agencias estatales, a los que nos referiremos más adelante. ${ }^{82}$

También se considera que los peritajes son una prueba idónea para demostrar hechos de contexto. Así se observa, por ejemplo, en el caso Moiwana, donde la Corte IDH utilizó las afirmaciones de dos antropólogos para referirse a cuestiones históricas sobre la sociedad N'djuka ${ }^{83} \mathrm{y}$ a aspectos pertinentes de dicha cultura. ${ }^{84}$ Asimismo, en el caso Carvajal $y$ otros c. Colombia, se citaron peritos y sus informes para referirse a un contexto de violencia en contra de periodistas. ${ }^{85}$

La Corte IDH también usa libros para probar elementos de contexto ${ }^{86}$. Los libros son simples instrumentos privados con ciertas características de edición y de formato. Por eso, su valor probatorio será el de un informe de una institución o un informe pericial o testimonio que no cumple con los requisitos para su presentación en juicio, dependiendo de quién sea el autor del mismo y de las fuentes que se utilicen al escribirlo.

Para probar cuestiones de contexto, la Corte IDH también utiliza normas legales, ${ }^{87}$ instructivos emanados de agencias estatales, ${ }^{88}$ planes

81 Artículo 28 del Estatuto de la Corte IDH. Algunos ejemplos donde eso ocurre son: López Lone y otros c. Honduras (2015): Corte IDH, Excepción Preliminar, Fondo, Reparaciones y Costas, Serie C no. 302, párrs. 46-49; Ramírez Escobary otros c. Guatemala (2018): Corte IDH, Fondo, Reparaciones y Costas, Serie C no. 351, nota al pie 47; Gonzálezy otras ("Campo Algodonero") c. México (2009): Corte IDH, Excepción Preliminar, Fondo, Reparaciones y Costas, Serie C no. 205, nota al pie 64.

82 Trabajadores de la Hacienda Brasil Verde c. Brasil (2016): Corte IDH, Excepciones Preliminares, Fondo, Reparaciones y Costas, Serie C no. 318, nota al pie 87.

83 V.gr., Comunidad Moiwana c. Surinam (2005): Corte IDH, Excepciones Preliminares, Fondo, Reparaciones y Costas, Serie C no. 124, párrs. 86.1 y ss.

84 V.gr., Ibíd., párrs. 86.6-86.8.

85 Carvajal Carvajal y otros c. Colombia (2018): Corte IDH, Fondo, Reparaciones y Costas, Serie C no. 352, notas al pie 17-22.

86 V.gr., Comunidad Moiwana c. Surinam (2005): Corte IDH, Excepciones Preliminares, Fondo, Reparaciones y Costas, Serie C no. 124, párr. 73.5; Herzog y otros c. Brasil (2018): Corte IDH, Excepciones Preliminares, Fondo, Reparaciones y Costas, Serie C no. 353, nota al pie 50.

87 V.gr., Trabajadores de la Hacienda Brasil Verde c. Brasil (2016): Corte IDH, Excepciones Preliminares, Fondo, Reparaciones y Costas, Serie C no. 318, notas al pie 95-102.

88 V.gr., Ibíd., nota al pie 76. 
nacionales, ${ }^{89}$ acuerdos celebrados entre las autoridades y ciertos grupos $^{90}$ y recortes de prensa. ${ }^{91}$ En general, cualquier medio probatorio que se genere con las debidas garantías y que sea valorado siguiendo las reglas de la lógica y la experiencia es un mecanismo idóneo para probar el contexto. Lo importante, más que el medio probatorio que se use, es que la Corte IDH relate solo los hechos de contexto indispensables para entender un caso, a menos que el contexto sea un hecho controvertido y esta le hubiera manifestado de algún modo a las partes que deben producir prueba sobre dicho punto.

La Corte IDH suele dar por probados ciertos hechos del contexto cuando una parte no desmiente las afirmaciones de la otra. Esto suele ocurrir con afirmaciones de la Comisión que no son controvertidas por el Estado. ${ }^{92}$ Esta forma de operar se parece a la aplicación que hace esta de la presunción establecida en el artículo 41.3 de su Reglamento, que dispone: "La Corte podrá considerar aceptados aquellos hechos que no hayan sido expresamente negados y las pretensiones que no hayan sido expresamente controvertidas". Este proceder es cuestionable, pues si el contexto no es parte del objeto del proceso, una parte no debe estar obligada a desmentir las afirmaciones de la contraparte en la materia.

\subsubsection{Estándar probatorio requerido para probar el contexto}

El estándar probatorio es "un umbral mínimo de convicción que debe generar la prueba antes de poder considerar probada una hipótesis". ${ }^{93}$ Conviene referirse al estándar que debe usar la Corte para dar por probado un hecho del contexto.

Cuando se trate de contextos de violaciones masivas, la Corte IDH debiera usar un estándar probatorio alto — si no de prueba más allá de toda

\footnotetext{
89 V.gr., Ibíd., nota al pie 91.

90 V.gr., Coc Maxy otros (Masacre de Xamán) c. Guatemala (2018): Corte IDH, Fondo, Reparaciones y Costas, Serie C no. 356, nota al pie 33.

91 V.gr., Velásquez Rodríguez c. Honduras (1988): Corte IDH, Fondo, Serie C no. 4, párr. 147.g.iii.

92 Comunidades Afrodescendientes desplazadas de la Cuenca del Río Cacarica (Operación Génesis) c. Colombia (Caso de las) (2013): Corte IDH, Excepciones Preliminares, Fondo, Reparaciones y Costas, Serie C no. 270, párr 85.

93 Álvaro Paúl Díaz, “Análisis sistemático de la evaluación de la prueba que efectúa la Corte Interamericana de Derechos Humanos", Revista Chilena de Derecho, 42 (2015): 317.
} 
duda razonable, al menos de prueba clara y convincente-, en atención a las consecuencias que ello puede traer a los Estados, ${ }^{94}$ pues los contextos de violaciones masivas pueden constituir la base para un razonamiento probabilístico que les sea contrario. Las demás cuestiones de contexto, tales como asuntos geográficos, históricos o culturales, no requerirían de la utilización de estándares altos, bastaría con uno de preponderancia de la prueba — aunque sería recomendable que este tipo de afirmaciones de contexto se reduzcan al mínimo necesario, ya que la Corte IDH no es geógrafa, ni historiadora ni socióloga, por lo que le será más fácil errar cuando incursione en estas áreas-.

\subsubsection{Idoneidad de los medios usados para probar el contexto}

Ahora analizaremos los medios de prueba en particular utilizados para dar por probado el contexto. Los hallazgos fácticos de la Corte IDH en casos anteriores no son un medio probatorio propiamente, sino el resultado de la aplicación de otros medios probatorios. Tales hallazgos deben presumirse verdaderos, pero tal presunción será solo una legal o iuris tantum, pues será posible que las partes presenten otras pruebas que sean más convincentes que las presentadas en el caso anterior.

Los informes son muy utilizados. Su idoneidad dependerá de la independencia y el carácter técnico del órgano que los emite y de la rigurosidad que se tuvo en su elaboración. Además, pueden influir otros elementos como si el informe se utiliza para probar algo contrario a los intereses de quien lo emite o el fin del mismo informe. Por eso no se puede dar una respuesta única sobre su valor probatorio. No obstante, debe reiterarse que generalmente no es adecuado utilizar únicamente informes de la Comisión Interamericana para dar por probado un hecho del contexto, ya que esta es una parte interesada en el proceso y podría haber redactado el informe teniendo a la vista el caso o su eventual presentación ante la Corte IDH. En el caso de los informes emanados de agencias estatales, a pesar de que ellos provengan del Estado, pueden ser bastante idóneos, especialmente cuando son preparados por agencias relativamente independientes y redactados en forma técnica, particularmente si contienen conclusiones que son desfavorables al Estado. Así, los informes estatales deberán ser revisados caso por caso, pues no procede descartarlos de plano, teniendo

94 Paúl, "Razonamiento...”, 63. 
en cuenta que el Estado es una institución de gran complejidad tanto por sus fines, como por su organización.

Los testimonios son poco idóneos para dar por probados hechos de contexto, por su inherente subjetividad (a menos que los testigos fueran muchos, cosa que es poco probable en los casos ante la Corte IDH). Lo anterior es especialmente así cuando quienes dan sus testimonios tienen interés en los resultados del juicio. ${ }^{95}$ Por su parte, las afirmaciones de peritos también deben ser tomadas con cierto recelo, en atención a que la subjetividad puede jugar un rol importante en sus informes, a pesar de que sean presentados como técnicos. Por eso, convendría que los peritajes sean usados en conjunto con otros medios para probar el contexto. No obstante, los peritajes son más idóneos para dar por probado el contexto que los testimonios.

Los recortes de prensa expresan el punto de vista de un periodista, por lo que pueden asemejarse a una prueba testifical o a una pericial. Su mayor o menor confiabilidad dependerá de la reputación del periodista, del medio de comunicación donde aparezca la noticia, así como de la claridad en la historicidad del hecho ocurrido. ${ }^{96}$ En este último punto, la Corte IDH suele afirmar que las notas de prensa "podrán ser apreciadas cuando recojan hechos públicos y notorios o declaraciones de funcionarios del Estado, o cuando corroboren aspectos relacionados con el caso". ${ }^{97} \mathrm{La}$ referencia a "hechos públicos y notorios" parece hacerse en un sentido no técnico, ${ }^{98}$ lo que significa que un hecho sería popularmente conocido.

Las normas, como constituciones y leyes, y los instructivos emanados de agencias estatales son medios de prueba idóneos para demostrar cuál

95 Por ejemplo, la Corte IDH se basa en testimonios de personas interesadas en García Lucero y otras c. Chile (2013): Corte IDH, Excepción Preliminar, Fondo y Reparaciones, Serie C no. 267, notas al pie 49-52.

96 En general, sobre el valor probatorio de las notas periodísticas, con particular referencia a la jurisprudencia colombiana, véase: Germán Suárez-Castillo, "El valor probatorio de las publicaciones periodísticas". Palabra Clave 11, no. 2 (2008).

97 V.gr., López Lone y otros c. Honduras (2015): Corte IDH, Excepción Preliminar, Fondo, Reparaciones y Costas, Serie C no. 302, párr. 32.

98 En realidad, los hechos notorios son hechos que, según la mayoría de los autores, no requieren prueba (notoria non egent probatione), por ejemplo, que un embarazo no puede durar un año. Véase: Hernando Devis Echandía, Teoría general de la prueba judicial. Tomo I. (Bogotá: Editorial Temis, 2015), 203-20.

En cambio, los hechos del contexto son siempre probados por la Corte IDH y han sido, incluso, discutidos por el Estado. 
es o era la configuración de un ordenamiento jurídico en un momento determinado, al menos de iure, pues la práctica jurídica dentro de un Estado podría violar las normas referidas, en cuyo caso habría que probar dicho incumplimiento de algún modo. Por su parte, los planes nacionales y los acuerdos celebrados entre las autoridades y ciertos grupos son ideales para probar la existencia de políticas públicas y, en cierta medida, su modo de ejecución.

\section{Conclusiones}

El relato de los contextos históricos, sociales y políticos de las alegadas violaciones de derechos humanos cumple un rol importante en las sentencias de la Corte IDH. En efecto, esta considera que el contexto puede calificar la responsabilidad del Estado (determinando si una violación forma parte de un patrón masivo y sistemático de violaciones); sirve como base para presunciones que pueda hacer en casos concretos; ayuda a determinar las reparaciones que puede imponer como garantías de no repetición, y es útil para determinar si una investigación nacional fue adecuada en casos en que la violación investigada formaba parte de un contexto de violaciones.

La Corte IDH no es el único tribunal internacional que hace uso del contexto al momento de fallar. Tanto la CIJ como el TEDH hacen uso del contexto. Sin embargo, estos le dan un uso más limitado, y es fácil entender por qué, porque la utilización del contexto puede presentar varios problemas que la misma Corte IDH ha experimentado. En efecto, es posible que se termine declarando en el contexto la existencia de violaciones ocurridas en un tiempo en el que la Corte IDH carecía de competencia o puede referirse a un Estado que, al no ser parte del caso, no ha contado con las garantías del debido proceso. Además, el contexto no forma parte del objeto del proceso ante esta, por lo que termina extendiendo dicho objeto cuando trata al contexto como una cuestión primordial.

Es necesario prestar atención a los medios de prueba que se utilizan para probar el contexto pues no todos son igualmente idóneos para hacerlo. Además, el estándar probatorio que se utilice debe adecuarse a los potenciales efectos del contexto que se describe (no es lo mismo relatar en el contexto violaciones masivas que otras cuestiones más generales). En definitiva, relatar el contexto puede ser muy útil, pero la Corte IDH debe evitar hacer afirmaciones discutibles o que puedan generar críticas por constituir una extensión de su competencia o un uso inadecuado de sus potestades. 


\section{Referencias}

Antkowiak, Thomas M. "Remedial Approaches to Human Rights Violations: The Inter-American Court of Human Rights and Beyond." Columbia Journal of Transnational Law 46, no. 2 (2008): 351-419.

Castañeda Quintana, Luisa Fernanda. "El contexto como materialización de la prueba indiciaria en la Corte Interamericana de Derechos Humanos". Revista Nueva Época 37, (2011): 99-124.

Cavallaro, James L \& Brewer, Stephanie Erin. "Reevaluating Regional Human Rights Litigation in the Twenty-First Century: The Case of the Inter-American Court." The American Journal of International Law 102, no. 4 (2008): 768-827.

Comisión Interamericana de Derechos Humanos. Derecho a la verdad en América, (OEA/Ser.L/V/II.152, Doc. 2, 2014). Recuperado de http:// www.oas.org/es/cidh/informes/pdfs/Derecho-Verdad-es.pdf

Devis Echandía, Hernando. Teoría general de la prueba judicial. Tomo I. Bogotá: Editorial Temis, 2015.

Londoño Lázaro, María Carmelina. Las garantías de no repetición en la jurisprudencia interamericana. Derecho internacionaly cambios estructurales del Estado. México D.F.: Tirant lo Blanch, 2014.

Paúl Díaz, Álvaro. "Razonamiento probabilístico de la Corte Interamericana para probar violaciones ocurridas en un contexto de atropellos masivos". Anuario de Derecho, no. 29 (2012): 43-73.

Paúl Díaz, Álvaro. "Análisis sistemático de la evaluación de la prueba que efectúa la Corte Interamericana de Derechos Humanos”. Revista Chilena de Derecho 42, no. 1 (2015): 297-327.

Roht-Arriaza, Naomi. "Measures of Non-Repetition in Transitional Justice. The Missing Link?” En From Transitional to Transformative Justice, editado por Paul Gready y Simon Robins, 105-130. Cambridge University Press, 2019.

Sierra Porto, Humberto. "La utilización del contexto en la jurisprudencia de la Corte Interamericana de Derechos Humanos". Filmada el 29 de marzo de 2016, Universidad Pompeu Fabra, Barcelona, España, video. Recuperado de https://www.youtube.com/ watch? $\mathrm{v}=8 \mathrm{x} 1 \mathrm{vlVAP} 8 \mathrm{VU}$

Suárez-Castillo, Germán. "El valor probatorio de las publicaciones periodísticas". Palabra Clave 11, no. 2 (2008): 157-64.

Taruffo, Michele. La prueba. Madrid: Marcial Pons, 2008. 


\section{Sentencias}

Abrill Alosilla y Otros c. Perú (2011): Corte IDH, Fondo, Reparaciones y Costas, Serie C no. 235.

Ahmadou Sadio Diallo (República de Guinea c. República Democrática del Congo) (2010): CIJ, Sentencia, 30 de noviembre.

Al Nashiri c. Polonia (2011): TEDH, 28761/11, 30 de noviembre.

Almonacid Arellano y Otros c. Chile (2006): Corte IDH, Excepciones Preliminares, Fondo, Reparaciones y Costas, Serie C no. 154.

Alemania c. Italia (2012): CIJ, Sentencia, 3 de febrero.

Big Brother Watch c. El Reino Unido (2018): TEDH, 58170/13, 62322/14 y 24960/15, 13 de septiembre.

Bolivia c. Chile (2018): CIJ, Sentencia, 1 de octubre.

Cabrera García y Montiel Flores c. México (2010): Corte IDH, Excepción Preliminar, Fondo, Reparaciones y Costas, Serie C no. 220.

Carvajal Carvajaly Otros c. Colombia (2018): Corte IDH, Fondo, Reparaciones y Costas, Serie C no. 352.

Castillo Gonzálezy Otros c. Venezuela (2012): Corte IDH, Fondo, Serie C $\mathrm{N}^{\circ} 256$.

Coc Maxy Otros (Masacre de Xamán) c. Guatemala (2018): Corte IDH, Fondo, Reparaciones y Costas, Serie C no. 356.

Comunidad Indigena Sawhoyamaxa c. Paraguay (2006): Corte IDH, Fondo, Reparaciones y Costas, Serie C no. 146.

Comunidad Indígena Xákmok Kásek c. Paraguay (2010): Corte IDH, Fondo, Reparaciones y Costas, Serie C no. 214.

Comunidad Moiwana c. Surinam (2005): Corte IDH, Excepciones Preliminares, Fondo, Reparaciones y Costas, Serie C no. 124.

Comunidades Afrodescendientes desplazadas de la Cuenca del Río Cacarica (Operación Génesis) c. Colombia (Caso de las) (2013): Corte IDH, Excepciones Preliminares, Fondo, Reparaciones y Costas, Serie C N²70.

Costa Rica c. Nicaragua (2009): CIJ, Sentencia, 13 de julio.

El-Masric. Antigua República Yugoslava de Macedonia (2012): TEDH, 39630/09, 13 de diciembre.

Furlany Familiares c. Argentina (2012): Corte IDH, Excepciones Preliminares, Fondo, Reparaciones y Costas, Serie C no. 246.

García Lucero y otras c. Chile (2013): Corte IDH, Excepción Preliminar, Fondo y Reparaciones, Serie C no. 267.

Goiburú y Otros c. Paraguay (2006): Corte IDH, Fondo, Reparaciones y Costas, Serie C no. 153. 
González Medina y Familiares c. República Dominicana (2012): Corte IDH,

Excepciones Preliminares, Fondo, Reparaciones y Costas, Serie C no. 240.

Gonzálezy Otras (“Campo Algodonero”) c. México (2009): Corte IDH, Excepción Preliminar, Fondo, Reparaciones y Costas, Serie C no. 205.

Gudiel Álvarezy Otros ("Diario Militar") c. Guatemala (2012): Corte IDH, Fondo, Reparaciones y Costas, Serie C no. 253.

Hermanas Serrano Cruzc. El Salvador (Caso de las) (2005): Corte IDH, Fondo, Reparaciones y Costas, Serie C no. 120.

Hermanos Landaeta Mejias y Otros c. Venequela (2014): Corte IDH, Excepciones Preliminares, Fondo, Reparaciones y Costas, Serie C no. 281.

Herzogy Otros c. Brasil (2018): Corte IDH, Excepciones Preliminares, Fondo, Reparaciones y Costas, Serie C no. 353.

López Lone y Otros c. Honduras (2015): Corte IDH, Excepción Preliminar, Fondo, Reparaciones y Costas, Serie C no. 302.

Luna López c. Honduras (2013): Corte IDH, Fondo, Reparaciones y Costas, Serie C no. 269.

Miembros de la Aldea Chichupac y comunidades vecinas del Municipio de Rabinal c. Guatemala (2016): Corte IDH, Excepciones Preliminares, Fondo, Reparaciones y Costas, Serie C no. 328.

Omar Humberto Maldonado Vargas y otros c. Chile (2015): Corte IDH, Fondo, Reparaciones y Costas, Serie C no. 300.

Pueblo Saramaka c. Surinam (2007): Corte IDH, Excepciones Preliminares, Fondo, Reparaciones y Costas, Serie C no. 172.

Pueblos Kalina y Lokono c. Surinam (2015): Corte IDH, Fondo, Reparaciones y Costas, Serie C no. 309.

Ramírez Escobary Otros c. Guatemala (2018): Corte IDH, Fondo, Reparaciones y Costas, Serie C no. 351.

Refah Partisi (The Welfare Party) y Otros c. Turquia (2003): TEDH, 41340/98, 41342/98, 41343/98 y 41344/98, 13 de febrero.

Rodríguez Vera y otros (Desaparecidos del Palacio de Justicia) c. Colombia (2014):

Corte IDH, Excepciones Preliminares, Fondo, Reparaciones y Costas, Serie C no. 287.

Sánchez, Juan Humberto c. Honduras (2003): Corte IDH, Excepción Preliminar, Fondo, Reparaciones y Costas, Serie C no. 99.

Sayği c. Turquí (2015): TEDH, 37715/11, 27 de enero.

Terrones Silva y otros c. Perú (2018): Corte IDH, Excepciones Preliminares,

Fondo, Reparaciones y Costas, Serie C no. 360. 
Trabajadores de la Hacienda Brasil Verde c. Brasil (2016): Corte IDH, Excepciones Preliminares, Fondo, Reparaciones y Costas, Serie C no. 318. Tribunal Constitucional (Camba Campos y Otros) c. Ecuador (Caso del) (2013): Corte IDH, Excepciones Preliminares, Fondo, Reparaciones y Costas, Serie C no. 268.

Velásquez Rodríguez. Honduras (1988): Corte IDH, Fondo, Serie C no. 4.

\section{Normas y tratados}

Convención Americana sobre Derechos Humanos.

Estatuto de la Corte Interamericana de Derechos Humanos.

Estatuto de Roma de la Corte Penal Internacional. 